\title{
Axé, práticas corporais e Aids nas religiões africanistas do Recife, Brasil
}

\author{
Axé, corporal practices, and Aids in Africanist religions \\ in Recife, Brazil
}

Luis Felipe Rios ${ }^{1}$

Cinthia Oliveira ${ }^{2}$ Jonathan Garcia ${ }^{3}$ Richard Parker ${ }^{3}$

\footnotetext{
${ }^{1}$ Departamento de Psicologia, Centro de Filosofia e Ciências Humanas, Universidade Federal de Pernambuco. Av. Acadêmico Helio Ramos CFCH/9, Cidade Universitária. 50.670-901 Recife PE Brasil. lfelipe.rios@gmail.com ${ }^{2}$ Universidade Federal de Santa Catarina.

${ }^{3}$ Columbia University.
}

\begin{abstract}
This article analyzes the responses of Afro-Brazilian religions to the Aids epidemic in Recife, taking into consideration the religious symbolic structure. Drawing on participant observation and in-depth interviews conducted with AfroBrazilian religious leaders and public health officials, it highlights the importance of "axé" - the native category used to interpret corporal events in order to understand the history of Aids in this religious community. Axé is mystical energy, corporal vitality. It is manipulated in religious rituals and is symbolically associated with blood, perspiration and semen. In these times of HIV, the body scarification rituals and exchanges of fluids during sexual exchanges are the ways by which axé circulates among adept and are the core elements for its promotion, though they have also become a means for the transmission of the HIV virus. These elements were the basis of the dialogue between religious institutions and the public health system. This process generated changes in religious practices for regulation of social reproduction and the sexual life of the adepts.
\end{abstract}

Key words Afro-Brazilian religions, HIV/Aids, Sexuality, Body
Resumo Este artigo analisa as respostas das religiões afro-brasileiras à epidemia de Aids no Reci$\mathrm{fe}$, considerando a estrutura simbólica religiosa. Baseando-se em observações participantes e em entrevistas em profundidade realizadas com líderes religiosos afro-brasileiros e técnicos de saúde pública e de ONG, destaca a importância do "axé", a categoria nativa utilizada para pensar os eventos corporais, para entender a história da Aids nessa comunidade religiosa. Axé é energia mística, vitalidade corporal. Ele é manipulado em rituais religiosos e simbolicamente associado a sangue, suor e sêmen. Nos tempos de HIV, os rituais de escarificação corporais e a troca de fluidos $d u$ rante as transações sexuais, formas para a circulação do axé e elementos-chave para o cultivo deste, também se tornam meio para a transmissão do $H I V$. Esses elementos foram o foco do diálogo entre as instituições religiosas e o sistema de saúde pública, um processo que gerou mudanças nas práticas religiosas de regulação da reprodução social e da vida sexual dos adeptos.

Palavras-chave Religiões afro-brasileiras, HIVI Aids, Sexualidade, Corpo 


\section{Introdução}

Neste artigo analisamos o engajamento de terreiros africanistas da Região Metropolitana do Recife na prevenção do HIV/Aids, considerando a estrutura simbólica religiosa. Passadas mais de duas décadas de epidemia, crenças religiosas têm mediado atitudes e políticas com ela relacionadas, e organizações religiosas têm sido centrais nas respostas ao HIV/Aids em países de todo o mundo. No contexto internacional, as pesquisas tendem a focar o papel das crenças e da espiritualidade em lidar com a infecção pelo HIV e com o luto ${ }^{1-3}$, e o papel dos valores religiosos na construção de programas educacionais em Aids ${ }^{4-6}$. No Brasil, não obstante a complexidade da atuação religiosa em HIV/Aids e seus impactos contraditórios, ainda são parcas as reflexões e pesquisas sobre o papel social e político das instituições religiosas $^{7-11}$.

Nos estudos sobre as religiões afro-brasileiras, as questões relacionadas com saúde e doença, cura e apoio comunitário para os aflitos se tornaram objeto de estudos de vários pesquisadores $^{12-14}$. Não obstante, a literatura que trata especificamente da Aids nesse universo ainda é bastante diminuta. Os trabalhos acadêmicos identificados tiveram como contexto, em sua grande maioria, o Sudeste do país, mais especificamente o Rio de Janeiro ${ }^{15-17}$. Talvez isso revele a própria dinâmica da epidemia, que vem afetando mais expressivamente o Sudeste. É importante lembrar que as ações de prevenção nos terreiros foram impulsionadas por importantes ONG. Conforme Wiik ${ }^{15}$, o uso compartilhado da navalha para as escarificações corporais em alguns rituais e a presença de homossexuais nos terreiros foram elementos mobilizadores para que as ONG pensassem em ações específicas para esse público. Nessa linha, tanto as ações do projeto Odoyá da Arca/Instituto Superior de Estudos da Religião (Iser) quanto as do projeto Arayê da Associação Brasileira Interdisciplinar de Aids (Abia) estão documentadas em trabalhos acadêmicos como os de Guimarães ${ }^{16}$ e Mesquita ${ }^{17}$.

Esses e outros estudos apontam como as crenças e as práticas de algumas dessas comunidades religiosas foram usadas para abordar populações estigmatizadas, discriminadas e economicamente marginalizadas ${ }^{18}$. A presença das religiões afro-brasileiras entre os segmentos mais pobres da população brasileira é percebida pelas instâncias governamentais de gestão da saúde com potencial para desempenhar um papel importante na resposta à epidemia em diversas fren- tes ${ }^{7,19,20}$, inclusive embasando-se na concepção dos centros religiosos afro-brasileiros como comunidades promotoras de saúde, como propõe o documento da política para a população negra do Ministério da Saúde ${ }^{21}$.

Os aspectos supracitados apontam para a necessidade de compreender melhor como nelas se realizam as concepções e as práticas corporais de cuidado de saúde em HIV/Aids, considerando a diversidade de denominações religiosas espalhadas pelo país e a interlocução que elas estabelecem com atores da sociedade abrangente. Nesse contexto, teorizar sobre corpo e saúde tornase fundamental para constituir ferramentas de investigação.

\section{Marco teórico}

Le Breton ${ }^{22}$ lembra que o próprio termo "corpo" foi constituído dentro do quadro da filosofia do sujeito ocidental, situado pelo cartesianismo, no apartamento entre a matéria/corpo e a razão/ mente. Corpo se configura, então, em uma categoria carregada dos sentidos com os quais a sociedade ocidental se concebe. Como tentativa de escapulir da armadilha que a noção de corpo poderia pressupor, impedindo que alcançássemos uma lógica diferente de constituir o objeto, buscamos, na esteira de Le Breton, as modalidades físicas de relação com o mundo, como expressas pelo candomblé e pelo xangô. De outro modo, investigamos como os religiosos africanistas do Recife constituem, em seus próprios termos, o enraizamento de seus integrantes no mundo, o que nos levou à elaboração de uma abstração analítica, a corporeidade religiosa africanista. Seguindo a proposta do autor, sugerimos que a corporeidade (corporéité) deve ser compreendida como uma estrutura simbólica, efeito das condições sociais humanas na lida com o meio humano de experimentação da realidade ${ }^{23}$.

Para dar conta das recorrências e das mudanças próprias à dinâmica sociocultural, assumimos a perspectiva da antropologia histórica de Sahlins ${ }^{24,25}$, tomando a distinção entre estrutura e evento para realizar uma antropologia dos processos de significação. Utilizamo-nos do termo corporeidade para falar da primeira e guardamos o termo corporalidade para a dimensão evento: distintas manifestações de dada corporeidade, quando atualizada em determinado contexto e/ou pessoa, no processo de oferecer significado a acontecimentos específicos - de outro modo, para pensar a variabilidade das formas que dada corporeidade pode tomar ${ }^{23,26}$. 
No campo de estudos socioculturais do corpo, a noção de corporeidade vem assumindo diferentes definições. Ao lado da proposta conceitual de Le Breton ${ }^{22}$, outra bastante expressiva é a formulada por Csordas ${ }^{27}$. Corporeidade foi o termo adotado para traduzir embodiment na versão brasileira de um dos mais influentes livros do autor. Tendo como referência a fenomenologia da percepção de Maurice Merleau-Ponty e a teoria do habitus de Bourdieu, Csordas se propõe estudar como se constitui a emergência de sentidos intersubjetivos na experiência somática dos atores, que envolve aspectos pré-objetivos, ainda que situados social e culturalmente. Assim, o embodiment de Csordas falaria do meio do caminho, do processo de corporificação, da corporéitélestrutura em corporalidade/evento.

Por aproximações, nosso conceito de corporeidade, como os aspectos estruturais que sustentam dada objetificação, seria uma alternativa ao de habitus bourdieusiano. Nossa opção em conceber a estrutura a partir de Sahlins ${ }^{24,25}$, e não de Bourdieu ${ }^{28}$, é uma tentativa de escapar da crítica formulada pelo próprio Csordas em relação à precariedade analítica do habitus para "explicar mudança, criatividade, inovação, transgressão e violação" 27 . A grade teórica de Bourdieu "esfria" os processos culturais, tendendo a fazer aparecer muito mais as recorrências que as mudanças. A ênfase nos processos de mudança dada por Sahlins nos abre mais possibilidades interpretativas quando estão sendo analisados processos históricos e, sobretudo, quando se tenta oferecer subsídios para a construção de boas práticas em futuras ações em saúde nos terreiros. Ao longo da pesquisa, buscamos, então, as categorias nativas que falam do enraizamento e como elas medeiam o encontro entre os terreiros afro-brasileiros e o HIV e a Aids - estes últimos já significados pelo discurso biomédico.

\section{Metodologia}

Para dar conta da diversidade de denominações de religiões afro-brasileiras, suas aproximações e particularidades, não apenas no Recife, mas nas outras três localidades onde o estudo foi desenvolvido, categorizamos as várias denominações em duas grandes matrizes: a) religiões africanistas, grosso modo, as que almejam uma proximidade maior com as culturas africanas: xangô e candomblé; e b) religiões de encantaria, grosso modo, as que se aproximam do cristianismo mediúnico (kardecista), articulado com o catolicis- mo popular, a magia europeia e as religiosidades indígenas e africanistas: jurema e umbanda ${ }^{29-31}$. Essas duas matrizes religiosas foram retomadas no campo do Recife como categorias "de entrada" para orientar a pesquisa. As distinções são puramente metodológicas, servindo como tipos ideais $^{32}$ que nos auxiliem a encontrar força analítica que tencione a realidade e possibilitem reflexões.

A pesquisa de campo aconteceu entre 2005 e 2008. Embasada em uma perspectiva etnográfi$\mathrm{ca}$, envolveu entrevistas de diferentes modalidades (informante-chave, em profundidade, história de vida e história oral) com nove sacerdotes - três da umbanda, dois do candomblé (nações ketu e angola), três do xangô (nações xambá e nagô) e uma da jurema -e 10 representantes de organizações governamentais e não governamentais envolvidos na mobilização religiosa para o enfrentamento da Aids - um total de 43 entrevistas. Também foram consideradas como recursos para coleta de dados inúmeras conversas informais com religiosos e com diferentes profissionais que atuaram junto aos terreiros na resposta à epidemia.

Além das entrevistas, foram realizadas observações participantes em casas de diferentes tradições e em atividades promovidas pela Rede Nacional de Religiões Afro-brasileiras e Saúde e pelas Secretarias de Saúde do Estado de Pernambuco e da Cidade do Recife relacionadas com o enfrentamento da epidemia de HIV/Aids. Vale, também, ressaltar que o pesquisador responsável por conduzir o trabalho de campo no Recife vem, desde 1994, desenvolvendo estudos etnográficos sobre gênero e sexualidade nesse universo religioso, os quais possibilitaram um $b a-$ ckground compreensivo das concepções nativas de enraizamento, sexualidade e saúde, que puderam ser aprofundados na interface com questões específicas à prevenção do HIV/Aids.

Privilegiaremos, neste artigo, o modo como os terreiros africanistas responderam à epidemia de HIV/Aids em termos de prevenção. Embora, quando conveniente, também serão trazidas para análise informações apresentadas por sacerdotes da jurema e da umbanda, deixaremos para um momento oportuno uma análise que enfoque as semelhanças e distinções entre africanistas e encantarias; do mesmo modo, uma análise da apreensão das pessoas vivendo com HIV no âmbito dos terreiros.

No processo analítico buscamos realizar uma descrição densa ${ }^{33}$, permitindo a emergência de categorias êmicas, a interpretação dos nativos e sua utilização como cultura na prática ${ }^{25}$, sem nos 
furtarmos a oferecer nossa própria interpretação do fenômeno objeto de nossa investigação, à luz do referencial teórico que enfatiza a construção sociocultural dos eventos corporais apresentados, em um movimento caracterizado por Giddens como dupla hermenêutica ${ }^{34,35}$. A pesquisa seguiu o preconizado pela Resolução CNS nº 196/ $1996^{36}$ e foi aprovada pelo Conselho Nacional de Ética em Pesquisa. De modo a guardar o sigilo e o anonimato dos informantes, utilizamos pseudônimos para identificá-los.

\section{Resultados}

Apresentado o enquadre teórico-metodológico em que os dados e as análises foram constituídos, iniciaremos nossa discussão situando o leitor em relação à corporeidade africanista. Em seguida, apresentamos o contexto de encontros entre organizações governamentais, não governamentais e religiosas que permitiram surgir uma resposta religiosa afro-brasileira ao HIV/Aids. Um encontro de sistemas de saberes e práticas vai possibilitar a emergência dos eventos analisados em duas frentes: em Oberés, analisamos o debate sobre as escarificações corporais, elemento importante para a iniciação nos cultos, entendido pela saúde pública como uma possível via para a infecção pelo HIV; em Acoxebés, refletimos sobre ações de prevenção que focam a vida sexual dos adeptos.

\section{Axé e a corporeidade africanista}

O candomblé e o xangô se constituem em religiões sacrificiais e politeístas, em que as divindades são relacionadas com os fenômenos naturais e são patronos de atividades sociais, tomando o corpo dos fiéis por meio da possessão. Os "terreiros" existem para que sejam viabilizados contatos favoráveis entre "aiê" (mundo) e "orun" (outro mundo). Pessoas são iniciadas como sacerdotisas da religião, aprendendo, com o galgar de uma hierarquia, os "fundamentos"/segredos para o serviço religioso. Uma metáfora familiar é utilizada para nomear a hierarquia que se forma dentro de um terreiro; assim, "pai" ou "mãe de santo" se configuram como sacerdotes supremos, auxiliados em seus serviços por outros sacerdotes, os "filhos e filhas de santo".

É nesse contexto familiar que devemos pensar a reprodução social dos terreiros. Os nascimentos que ali importam são os de novas "iaôs" (esposas mais novas do "orixá"), que se fazem por via de procedimentos rituais: a "feitura"/iniciação. Considerado um nível descritivo-analítico mais abstrato, que dê conta de uma diversidade de procedimentos específicos a cada terreiro, esse ritual se faz inculcando em uma pessoa (entendida como suporte para que os entes espirituais se manifestem) o axé (energia) de determinada linhagem espiritual de parentesco.

Energia e linhagem, entretanto, são palavras que dizem muito pouco de axé. Para ampliar a compreensão, precisamos situá-la em suas principais características. Assim, na crença africanista, existem qualidades de axé, que podem ser positivas e negativas para dada pessoa ou coletividade. $\mathrm{O}$ axé pode ser acumulado, transmitido e perdido. Por onde ele migra, ou flui, transmite traços de seus antigos depositários. Parece-nos que a noção de axé como linhagem vem dessa ideia de que, ao fluir, as energias, que possuem qualidades específicas, marcam as coletividades.

No que se refere à pessoa, esta é concebida como recebendo uma quantidade e qualidade de axé para ganhar existência no aiê, mas, ao longo da vida, a quantidade pode mudar. A variação é apreendida por meio de sinais no corpo e nas relações sociais. A doença, o sofrimento, a fadiga se apresentam quando o axé diminui, ou se entra em contato com um axé com o qual não se é afim. Quando o axé é benfazejo e aumenta, o ser prospera em todas as áreas. Cabe à religião intervir, buscando reforçar o fluxo e acúmulo de axé positivo por meio de rituais que religam o mundo e o outro mundo ${ }^{14}$.

Também é importante frisar o caráter concreto do axé. Ele sempre precisará de um suporte para se expressar ou passar de um ser a outro. Assim, o sangue dos animais e suas vísceras são axé. Por extensão, o sangue e a própria interioridade corporal humana são a fonte e/ou o suporte da vitalidade individual. Nessa linha, os adeptos concebem que os fluidos corporais podem levar axé de parte a parte. A saliva do sacerdote, elemento-chave em vários processos rituais, está carregada de axé, bem como o suor que desce da face dos filhos de santo em transe de orixá, os quais carinhosamente o passam, para transmiti-lhes benesses, no corpo de seus acólitos. Também o sêmen, resultante das transações sexuais, faz o axé caminhar de pessoa a pessoa.

Em nossa interpretação, esse é o esquema conceitual mais amplo, a corporeidade africanista, que orienta as apreensões sobre os eventos corporais e que se atualiza em face do risco empíri$\mathrm{CO}^{24}$ que o HIV e os discursos de saúde pública 
sobre ele apresentam para as comunidades religiosas. Ao longo do texto, quando necessário, estaremos aprofundando os meandros dessas incorporações e transmissões de axé, nos modos como se desdobra nas questões que são caras à epidemia de Aids, como informada pelas ciências da saúde - um vírus que se propaga pelos fluidos corporais, em especial o sangue, e que tem nas relações sexuais um dos principais acontecimentos para a infecção.

\section{Aids e as comunidades religiosas}

A resposta das religiões afro-brasileiras no Recife ao HIV e à Aids se inicia de forma sistematizada em 2000, a partir da atuação da Coordenação Estadual de DST/Aids da Secretaria de Saúde de Pernambuco (CE-DST/Aids). Ainda que vários religiosos entrevistados se referissem a um primeiro contato com pessoas vivendo com Aids anterior à chegada da Coordenação nos terreiros, foram as ações desta que possibilitaram uma maior reflexão e o engajamento em intervenções mais específicas.

O processo se deu a partir da organização de uma comissão, envolvendo pais e mães de santo, antropólogos e técnicos da CE-DST/Aids, para pensar ações de enfrentamento à epidemia nos terreiros. Nesse bojo, um dos principais insumos citados foi a cartilha Atotô, que trata, na linguagem dos terreiros, da transmissão do HIV por instrumentos perfurocortantes e das questões sexuais relacionadas com a epidemia. A cartilha foi distribuída juntamente com a realização de palestras em diversos terreiros.

Já em 2005, alguns de nós participamos de uma das capacitações, em que diversos pais e mães de santo estiveram presentes; em 2007, fomos convidados a participar de um Grupo de Trabalho sobre Religião e Aids, organizado pela Coordenação Municipal, o qual contou com a presença, dentre outros integrantes, de alguns pais e mães de santo. Há, também, referência à atuação da Rede de Religiões Afro-brasileiras e Saúde, uma iniciativa não governamental de abrangência nacional. Nos relatos dos sacerdotes entrevistados, dois eixos se configuraram quando foram questionados sobre prevenção: os cortes rituais e as transações sexuais. Aprofundaremos cada um deles.

\section{Oberés: os cortes rituais}

À semelhança do que aconteceu no Rio de Janeiro ${ }^{15-17}$, o uso compartilhado de navalhas para a realização dos oberés, pequenas incisões na pele para a passagem do axé durante o processo iniciático, foi a preocupação inicial. Não obstante, enquanto no Rio de Janeiro foram as ONG que buscaram interferir no contexto, no Recife, a preocupação com o uso compartilhado da navalha foi trazida pelo Estado. Os cortes rituais são postos em causa pelo discurso da saúde pública, que informava que o vírus do HIV pode utilizar-se do compartilhamento de instrumentos cortantes para passar de um ser a outro.

Então, nos conscientizamos de que a navalha poderia ser um instrumento que levasse, colaborasse com o aumento da Aids nas comunidades. Isso não foi fácil, pra gente tirar isso. Porque, tinha, assim: 'Essa navalha era a navalha da casa, então todos têm que passar por ela.' 'Essa navalha é a navalha que veio do meu avô, então todos têm que passar por ela!' Era questão de tradição. [...] Não era uma questão ritualística, $e$, sim, uma questão de tradição. Uma coisa que estava na cabeça das pessoas. [...] Então, as pessoas não tinham sensibilidade a ponto de entender que poderiam prejudicar terceiros com o uso deste instrumento... (Pai João, xangô, 65 anos)

Vemos no relato do babalorixá os esforços para ressignificar o valor da navalha para o processo ritual: seu deslocamento como elemento ritualístico fundamental para uma "mera tradição". Ainda que o xangô e o candomblé sejam culturas fundadas na passagem oral do saber, o sacerdote menciona o recurso aos "livros" na busca de evidências de que a navalha e/ou seu uso compartilhado não são elementos de "fundamento":

Hoje, por exemplo, o nosso povo trabalha com navalha descartável. Porque, depois de uma pesquisa profunda, nós não encontramos em nenhum livro e em nenhuma história, a partir de África, que dissesse que aquele instrumento era o único instrumento que pudesse ser usado: que era a navalha conscientemente alemã. Que, na época, as primeiras navalhas eram alemãs. [...] A navalha apareceu apenas como instrumento mais propício para o corte. Era ela uma peça pequena, amolada, que era boa para raspar. O barbeiro já raspava a barba, e isso levou o pai do terreiro a entender que ela era boa para raspar e rapar a cabeça e fazer os cortes. Hoje nós trabalhamos com a navalha descartável, não tem como não trabalhar assim. (Pai João)

Assim, o caráter made in Alemanha das navalhas disponíveis no mercado foi mais um elemento citado para argumentar em prol das modificações necessárias, dada a presença do vírus 
invisivelmente circulando nas comunidades-terreiro. São omitidos por nosso interlocutor os elementos que pesam contra a proposta de individualizar a navalha, utilizada para a entrada do axé da linhagem no corpo dos iniciados, fazendo-os renascer para aquela família de santo. O axé precisa de condutores para passar de um ser a outro - a navalha, mas também todos os outros artefatos utilizados no processo. Ao receber a permissão dos orixás para iniciar novos filhos, o sacerdote recebe a navalha (dentre outros elementos) como símbolo de que está habilitado para iniciar novas iaôs. Essa navalha recebe sacrifícios, como todos os outros elementos ritualísticos dos terreiros, o que tem o sentido de se tornar instrumento sagrado, carregado de axé.

No ritual, como antes preconizado, a navalha, além de cortar, servia como um dos meios para incorporar o axé da tradição no indivíduo. Não era por "ignorância religiosa" que os sacerdotes afirmavam "Eu não vou trocar, não! Essa navalha é navalha da minha casa, do meu orixá! Meus filhos têm que passar por ela!", recusandose a incorporar a mudança. Eles estavam guardando os fundamentos - agindo em conformidade com a corporeidade afrorreligiosa. O fato é que, na disputa por sentido e significação, a mudança se deu: [Sobre a navalha:] Que tem que ser descartável e que aquilo não pode passar de um para o outro. [...] E na oficina eu já aprendi que a gente tem que botar numa latinha, botar vinagre, água sanitária, tampar e jogar fora num lugarzinho que, assim, ninguém possa pegar, né? (Pai Cláudio, candomblé, 50 anos).

Mas a resposta não se restringiu ao uso da navalha. Ela se dirigiu para outros usos dos corpos, em que o contato com seus fluidos pode ser o caminho para o vírus HIV se disseminar.

\section{Axoxebés: as transações sexuais}

Os estudos sobre as religiões afro-brasileiras, comparando-as às outras religiões integrantes do cenário brasileiro, apresentam-nas como mais permissivas no que se refere à moral sexual. Eles têm enfatizado a abertura dos terreiros africanistas para as homossexualidades ${ }^{37-42}$. Não obstante, apontam que, mesmo que o sistema de sexo-gênero dos terreiros não enfatize a regulação da vida sexual dos adeptos com base em de premissas que remetam o prazer sexual ao campo da reprodução e do matrimônio monogâmico, existem regras para o exercício da sexualidade que recaem na própria economia do axée $e^{43}$. É a partir do axé (energia/linhagem) que se dá a re- produção social das comunidades-terreiro. Considerando-se tais regras, nossos entrevistados apresentaram como repressoras em relação a determinados comportamentos sexuais as religiões que praticam:

O orixá proíbe que você faça determinadas coisas. Entre essas coisas estaria você ir à zona [de prostituição], por exemplo. [...] A chegar numa dama [prostituta], porque ele sabe que a mulher pega ele em todo o corpo, cabeça, pé... Então ele se assusta, um pouco, com isso. E ele tem medo, que o orixá, também, não castigue ele. [...], para a gente, é um ambiente onde tem as energias negativas. [...] Então, a contribuição que o candomblé dá é, exatamente, essa repressão. Vamos dizer, é... Essa prevenção, não repressão, e sim essa prevenção: 'Não vai porque você pode adoecer' - isso é prevenir! (Pai João)

Nossos entrevistados localizaram as normas sexuais dos terreiros como um fator a serviço da prevenção. Pai João, na citação anterior, orienta sua fala a partir da noção de corpo sujo/lim$\mathrm{po}^{14,44}$. Estar com o corpo limpo significa carregar energias positivas, um requisito para poder participar dos rituais, do mesmo modo que para ter saúde. Estar com o corpo sujo em um ritual é considerado falta grave, como ele sublinha: $\mathrm{Na}$ religião da gente, se você fizer sexo, você não pode participar do ritual, [...] a pessoa está de corpo sujo! De alma suja.

Por outro lado, ainda que os sacerdotes apontem as regras em relação ao exercício da sexualidade, também reconhecem a existência da possibilidade de escolhas pessoais. Ademais, ao lado das regras aparece a noção de "carne", como desejo sexual que constantemente se insurge contra o prescrito pela moral sexual, apresentando-se como um fator contribuinte para a infecção pelo vírus HIV e para a gravidez não planejada. Se Pai João nos fala de prescrições ideais para um adepto se conduzir sexualmente no mundo, ele próprio comenta: "Porque a carne não conhece obediência! A carne não deve respeito a nada e a ninguém! Se a carne reinar, acontece a qualquer momento, em qualquer idade e a qualquer lugar!"

Diferente do cristianismo, no qual a "carne" deve ser objeto de constante vigilância, entendida como fonte de pecado e só devendo ser vivida quando abençoada pelo sacramento do matrimônio ${ }^{9,11}$, no contexto das religiões afro-brasileiras ela é descrita como prazer, como um bem a ser desfrutado. A mitologia vai apresentar o desejo e o prazer sexual como fruição que possibilita a fecundidade e a fertilidade das pessoas, das comunidades e do mundo. 
Vários autores aludem a uma erotização discursiva generalizada envolvendo os sujeitos no cotidiano dos terreiros, o que acontece sem necessariamente se contrapor às regras e normas que situam os interditos sexuais sobre os quais Pai João nos falou ${ }^{40,41,43}$. Lembrando que onde há regras há possibilidades de transgressão, Rios ${ }^{45}$ apresenta como preceitos e práticas se inter-relacionam no contexto das experiências concretas dos adeptos, em uma trama em que as vivências sexuais das pessoas servem de indicadores para se aferir tanto a realidade do orixá de uma pessoa quanto o grau de tradicionalidade de determinado terreiro. Ele relata o caso de um recéminiciado que, não resistindo ao resguardo sexual, retira o "quelê" (colar que simboliza a submissão do iaô ao orixá), coloca-o no "assentamento" do santo e tem relações sexuais com o namorado. $\mathrm{O}$ comentário em outros terreiros próximos é da falta de seriedade do pai de santo, que não puniu a falta do rapaz. Não obstante, o fim do relacionamento entre este e o companheiro, em uma violenta briga acontecida às portas do terreiro poucos dias após a quebra de interditos, restituiu, de certa forma, a credibilidade das pessoas sobre o orixá, o fiel e o pai de santo, na medida em que foi concebida como castigo dos deuses.

Sobre as faltas cometidas em relação aos preceitos religiosos, Augras ${ }^{44}$ lembra que, no final das contas, as próprias transgressões são elementos importantes para incrementar o sistema de trocas entre o mundo e o outro mundo. Porque as faltas realizadas vão implicar reparações, atualizadas em rituais em que o axé desperdiçado ou poluído é restituído em forma de oferendas.

Assim, talvez por considerarem a coexistência entre preceitos e desejos para bem lidar com a carne, nossos informantes dizem ser preciso estimular o desenvolvimento nos indivíduos de responsabilidade:

[Sobre o momento ideal para iniciar a vida sexual] A partir do momento que ele passar a ter responsabilidade com as coisas. [...] Eu acredito em 40\% do jovem de 18 anos; nessa faixa, eles têm responsabilidade. Responsabilidade com a família. 'Bom, meu pai disse isso. Então eu vou obedecer.' Outros têm responsabilidade com a namorada, sabe e conhece a família da namorada e outros têm responsabilidade com si próprios: 'Eu não posso fazer isso porque não posso assumir filho'; 'Eu não quero estragar os meus estudos'; 'Eu não quero fazer isso, eu não quero fazer aquilo...' (Pai João)

Nesse contexto, a responsabilidade seria uma conquista no desenvolvimento pessoal, uma introjeção dos saberes e das normas sociais, que viria a se articular com o livre-arbítrio como uma forma de consciência das consequências dos atos, um dispositivo de segurança.

[Do seu ponto de vista, ou mesmo na religião, quando e em que situação os meninos devem começar a sua vida sexual?] Eu acho que é a partir da hora que ele tiver segurança. [...] Eu acho que o sexo não é coisa ruim, né? Eu acho até bom! Mas acho que, "pra" isso acontecer, a pessoa tem que saber o que quer com um parceiro ou uma parcei$r a$, e veja realmente o que ele esteja fazendo, né? Orientação. Procurar conversar sempre com os seus pais, que são as pessoas mais amigas que possam orientá-las. [...] Ela tendo segurança, realmente, $e$ vendo que aquilo é bom pra ela. E se ela souber que aquilo, ela vai se prevenir de uma Aids, saber como usar uma camisinha, se ela não quiser usar, pede 'pro' parceiro usar, 'pra' se prevenir de uma gravidez e de uma doença, né? E de uma gravidez indesejada, 'pra' depois não 'ta' sofrendo. (Pai Cláudio)

Pai João e Pai Cláudio nos falam da necessidade de desenvolver responsabilidade/segurança como forma de fazer frente às consequências adversas dos prazeres da carne. Rios et al. discutem a operação das noções de segurança e responsabilidade entre católicos e evangélicos ${ }^{9}$. Do mesmo modo que para os afro-brasileiros, o desenvolvimento da responsabilidade surge para aquelas tradições religiosas como modo de disciplinar a carne. Nesse âmbito, falar da incorporação das normas sociais por meio de responsabilidade e segurança parece indicar a existência de um diálogo sub-reptício entre os dispositivos religiosos com o discurso do risco, próprio às ciências médicas contemporâneas $^{46-48}$. É importante lembrar que são organizações governamentais que mobilizam os terreiros para resposta à epidemia, e estas chegam aos terreiros com um discurso fundado nas noções de risco e segurança ${ }^{9,49}$.

Em nossa interpretação, essa articulação entre dispositivos religiosos de sexualidade e dispositivos médicos acontece não apenas pelo status alcançado na sociedade contemporânea do discurso sobre o risco ${ }^{46}$, mas também porque os clérigos católicos, evangélicos e afro-brasileiros reconhecem o contexto atual em que os fiéis estão inseridos, expostos a múltiplas perspectivas sobre sexualidade presentes em instâncias e pensamentos laicos circulantes na sociedade abrangente. Eles se referem, em especial, às imagens e ideias sexuais veiculadas pela mídia:

Eu sou contra esse programa "Malhação" [novela de final de tarde], e vou the explicar por quê. Você vê em "Malhação" a meninada iniciar a vida sexual com o namorado. [...] Então, a menina que 
"ta" com o namoradinho dela, a gente não pode julgar, mas tem uma cabeça, vamos dizer assim, que "ta" no "baixo clero" [referência à sexualidade]. Aí vai e tem relações sexuais com ele. Depois que ela tem relações sexuais com ele, ele também não tem cabeça... (Pai Fernando, xangô, 53 anos)

Trata-se de um contexto em que se ampliaram os espaços de circulação dos jovens na sociedade, muitas vezes impedindo a eficácia dos mecanismos mais comunitários de controle - como a fofoca. Assim, em um ambiente social propício à emergência de processos como os de barganhas cognitivas entre ideais modernos laicos e religio$\operatorname{sos}^{50}$, o controle precisa estar no próprio indivíduo. É este quem precisa estar habilitado para realizar os cálculos de risco, cuja completa incorporação se revela na responsabilidade.

Reconhecendo os perigos e os prazeres do sexo e os limites da disciplina religiosa na proteção dos adeptos contra a Aids, todos os sacerdotes e sacerdotisas afro-brasileiros entrevistados afirmam a importância do trabalho de prevenção, nos moldes do preconizado pelas políticas públicas, acontecendo dentro de seus templos.

[O senhor lembra, assim, dessa primeira reunião? Como é que foi?] [...] Muitos que eu chamei também não vieram. "Ah! Quero saber, não, pai, dessas coisas, não! Eu não "tô" com Aids, eu não "tô" com nada". E eu digo, mas é o que eu estou dizendo a você, você não "tá", então dê graças a Deus. Mas tem que aprender já! "Pra" não pegar mesmo. [...] Eles já conversam, hoje em dia já sentame, às vezes, eles vêm até conversar comigo. (Pai Cláudio)

\section{Considerações finais}

Sacerdotes e técnicos da saúde pública avaliam como profícuo o contato entre eles, possibilitando o engajamento dos terreiros na prevenção do HIV/Aids. O uso da navalha e as questões de sexualidade são abertamente tratados, incluindo a distribuição de materiais informativos e de preservativos dentro dos terreiros.
Não obstante, o que é preconizado pela saúde pública não passou imune ao "pensamento nativo". Buscamos mostrar como as transformações observadas estiveram articuladas pela categoria axé. No que concerne à prevenção, o debate travado a partir da interpelação do Estado conseguiu situar o HIV como risco empíri$\mathrm{CO}^{24}$ relevante para exigir mudanças. Mostramos os caminhos que possibilitaram a ressignificação do abandono da navalha compartilhada. Também mostramos como a apreensão dos fluidos corporais como veículo de axé possibilitou entender o controle já existente sobre a sexualidade dos adeptos como estratégia protetiva contra a "poluição" pessoal pelo HIV.

Não obstante, quando a preocupação sexual se instala, ela se dá não apenas direcionada às pessoas com práticas homossexuais (preocupações em outros contextos e momentos da história do engajamento dos terreiros no enfrentamento da epidemia). Parece-nos que os beneficiários privilegiados das ações nos terreiros são os jovens, o que pode ser um reflexo do que era preconizado em termos de política de saúde em 2000. Desde 1999, o apelo aos jovens começa a aparecer nas campanhas nacionais de prenvenção ${ }^{51}$. Do mesmo modo, embora a reflexão sobre vulnerabilidade, que situa as condutas individuais e a exposição ao agravo nos contextos sociais e culturais ${ }^{9,52}$, estivesse em voga nas discussões acadêmicas, as práticas em saúde pública ainda se faziam no apelo ao indivíduo.

Em que pesem as críticas ao modelo individualizante apontado 9 , os religiosos aprenderam com a saúde pública uma importante lição: no contexto liberal da sociedade contemporânea, apelar para a construção de uma responsabilidade individualizada, a partir da ideia de segurança, é uma importante estratégia, junto com a distribuição de informação e camisinha, para garantir axé e saúde. Surge um discurso em que a economia política do axé é apreendida por estratégias biopolíticas de controle dos corpos e das populações. 


\section{Colaboradores}

Luis Felipe Rios coordenou o trabalho de campo no Recife e participou da análise, da interpretação dos dados e da redação do artigo; Cinthia Oliveira participou da coleta e da análise dos dados; Jonathan Garcia participou da coleta e da análise dos dados; Richard Parker foi responsável pela concepção e pelo delineamento geral da pesquisa mais ampla Respostas Religiosas à Epidemia de HIV/Aids no Brasil e participou da análise, da interpretação dos dados e da redação do artigo.

\section{Agradecimentos}

Este artigo analisa dados do projeto Respostas Religiosas ao HIV/Aids no Brasil, financiado pelo U.S. National Institute of Child Health and Human Development. Coordenador principal: Richard Parker (Columbia University). Realizado no Rio de Janeiro (coordenador: Veriano Terto Jr./Associação Brasileira Interdisciplinar de Aids); São Paulo (coordenadora: Vera Paiva/Universidade de São Paulo); Porto Alegre (coordenador: Fernando Seffner/Universidade Federal do Rio Grande do Sul); e Recife (coordenador: Luis Felipe Rios/Universidade Federal de Pernambuco). O conteúdo é de inteira responsabilidade dos autores e não representa a posição oficial do Eunice Kennedy Shriver National Institute of Child Health and Human Development ou do National Institutes of Health.

\section{Referências}

1. Coleman CL. The Contribution of religious and existential well-being to depression among African American heterosexuals with HIV infection. Issues Ment Health Nurs 2004; 25(1):103-110.

2. Woods T. Religion and spirituality in the face of illness: How cancer, cardiac, and HIV patients describe their spirituality/religiosity. J Health Psychol 1999; 4(4):393-412.

3. Fleck, MPA. O instrumento de avaliação de qualidade de vida da Organização Mundial da Saúde (WHOQOL-100): características e perspectivas. Cien Saude Colet 2000; 5(1):33-38.

4. Remle RC, Koenig HG. Religion and health in HIV/ Aids communities. In: Plante TG, Sherman AC, organizadores. Faith and health: Psychological perspectives. New York: Guilford; 2001. p. 195-212.

5. Edelheit, J. The passion to heal: a theological approach to HIV/Aids. Zygon 2004; 39(2):497-506.

6. Benton KW. Saints and sinners: Training Papua New Guinean christian clergy to respond to HIV and Aids using a model of care. J Relig Health 2008; 47(3):314-325.

7. Galvão J. As respostas religiosas frente à epidemia de HIV/Aids no Brasil. In: Parker R, organizador. Políticas, instituições e Aids: enfrentando a epidemia no Brasil. Rio de Janeiro: Jorge Zahar, Abia; 1997.

8. Seffner F, Silva C, Maksud I, Rios LF, Natividade M, Borges P, Terto Junior V, Parker R. Respostas religiosas à Aids no Brasil: impressões de pesquisa acerca da Pastoral de DST/Aids da Igreja Católica. Ciencias Sociales y Religión 2008; 10(10):151-174.

9. Rios LF, Paiva V, Maksud I, Oliveira C, Cruz CMS, Silva CG, Terto Junior V, Parker R. Os cuidados com a "carne" na socialização sexual dos jovens. Psicol. Estud. 2008; 13(4):673-682.

10. Silva CG, Santos AO, Licciardi DC, Paiva V. Religiosidade, juventude e sexualidade: entre a autonomia e a rigidez. Psicol. Estud. 2008; 13(4):683-692.

11. Rios LF, Aquino FL, Muñoz-Laboy M, Murray LR, Oliveira C, Parker RG. The Catholic Church, moral doctrine, and HIV prevention in Recife, Brazil: Negotiating the contradictions between religious belief and the realities of everyday life. Cult Relig 2012; 12(4):355-372.

12. Loyola MA. Médicos e curandeiros: conflito social e saúde. São Paulo: Difel; 1984.

13. Montero P. Da doença à desordem: a magia na umbanda. Rio de Janeiro: Graal; 1985.

14. Barros JF, Teixeira ML. O código do corpo: inscrições dos orixás. In: Moura C, organizador. Meu sinal está em teu corpo. São Paulo: Edicon, Edusp; 1989.

15. Wiik F. The cultural construction of Aids and its social disruptive nature: The case of candomblé (AfroBrazilian) religion [dissertação]. Oslo: Universidade de Oslo; 1994.

16. Guimarães MA. A rede de sustentação: um modelo winnicottiano de intervenção em saúde coletiva [tese]. Rio de Janeiro: Pontifícia Universidade Católica do Rio de Janeiro; 2001.

17. Mesquita RR. Viver e morrer em tempos de Aids: vida, morte e sexualidade em candomblés do Rio de Janeiro [tese]. Rio de Janeiro: Universidade Federal do Rio de Janeiro; 2002. 
18. Garcia J, Parker RG. Resource mobilization for health advocacy: Afro-Brazilian religious organizations and HIV prevention and control. Soc Sci Med 2011; 72(12):1930-1938.

19. Parker R. Building the foundations for the response to HIV/Aids in Brazil: The development of HIV/ Aids policy. Divulgação em Saúde para Debate 2003; 27:143-183.

20. Garcia J, Muñoz-Laboy M, Almeida V, Parker RG. Local impacts of religious discourses on rights to express same-sex sexual desires in periurban Rio de Janeiro. Sexuality Research and Social Policy 2009; 6(3):44-60.

21. Brasil. Política nacional de saúde integral da população negra. Brasília: Ministério da Saúde; 2007.

22. Le Breton D. Sociologia do corpo. Petrópolis: Vozes; 2006.

23. Rios LF. Corpos e prazeres nos circuitos de homossociabilidade masculina do Centro do Rio de Janeiro. Cien Saude Colet 2008; 13(2):465-475.

24. Sahlins M. Ilhas de história. Rio de Janeiro: Zahar; 1990

25. Sahlins M. Cultura na prática. Rio de Janeiro: UFRJ; 2004.

26. Fougeray S. Do corpo na antropologia à antropologia do corpo. In: Anais do V Encontro de Antropólogos do Norte-Nordeste; 1998; Recife: Universitária da UFPE.

27. Csordas T. Corpo/significado/cura. Porto Alegre: UFRGS; 2008

28. Bourdieu P. O poder simbólico. Rio de Janeiro: Bertrand Brasil; 2005.

29. Silva V. Candomblé e umbanda: caminhos da devoção brasileira. São Paulo: Ática; 1994.

30. Prandi R, organizador. Encantaria brasileira. Rio de Janeiro: Pallas; 2001.

31. Brandão MC, Rios LF. El campo religioso afrorecifense contemporâneo: nuevos modelos religiosos y políticas de identidade. In: Monter J, organizador. Integración social y cultural. Coruña: Universidade da Coruña; 2002.

32. Weber M. A objetividade do conhecimento nas ciências sociais. In: Conh G, organizador. Weber. São Paulo: Ática; 1989.

33. Geertz C. The interpretation of cultures. New York: Basic Books; 1973.

34. Giddens A. The constitution of society: on outline of the theory of structuration. Cambridge, Berkeley: University of California Press; 1984.

35. Ayres JR. Norma e formação: horizontes filosóficos para as práticas de avaliação no contexto da promoção da saúde. Cien Saude Colet 2004; 9(3):583592.

36. Brasil. Ministério da Saúde (MS). Conselho Nacional de Saúde. Resolução no 196 de 10 de outubro de 1996. Diretrizes e Normas Regulamentadoras de Pesquisas Envolvendo Seres Humanos. Diário Oficial da União 1996; 16 out.

37. Landes R. A cidade das mulheres. Rio de Janeiro: Civilização Brasileira; 1967.
38. Ribeiro R. Personalidade e ajustamento psicossexual dos fiéis dos cultos afro-brasileiros. In: Ribeiro R. Antropologia e outros estudos. Recife: Massangana; 1982.

39. Fry P. Para inglês ver: identidade e política na cultura brasileira. Rio de Janeiro: Zahar; 1982.

40. Teixeira ML. Lorogun: identidades sexuais e poder no candomblé. In: Moura C, organizador. Candomblé, desvendando identidades. Rio de Janeiro: EMW; 1987.

41. Segato R. Santos e daimones. Brasília: UnB; 1995.

42. Birman P. Fazendo estilo criando gênero. Rio de Janeiro: Relume-Dumará; 1995.

43. Rios LF. O paradoxo dos prazeres: trabalho, homossexualidade e estilos de ser homem no candomblé queto fluminense. Etnográfica 2012; 16(1): 53-74.

44. Augras M. O que é tabu. São Paulo: Brasiliense; 1989.

45. Rios LF. Loce, Loce, Metá Rê Lê! Homossexualidade e transe (tividade) de gênero no candomblé de nação [dissertação]. Recife: Universidade Federal de Pernambuco; 1997.

46. Caliman LV. Dominando corpos, conduzindo ações: genealogias do biopoder em Foucault. In: Jacó-Vilela AM, Cerezzo AC, Rodrigues H, organizadores. Clio-psyché - subjetividade e história. Juiz de Fora: Clio Edições Eletrônicas; 2006.

47. Foucault M. História da sexualidade I: a vontade de saber. Rio de Janeiro: Graal; 1993.

48. Foucault M. O sujeito e o poder. In: Dreyfus H, Rabinow P, organizadores. Michel Foucault, uma trajetória filosófica: para além do estruturalismo e da hermenêutica. Rio de Janeiro: Forense Universitária; 1995.

49. Brasil. Departamento de DST e Aids; s/d [site na Internet]. [acessado 2009 set 1]. Disponível em: http://www.aids.gov.br/main.asp?View $=\{$ CEBD 192A-348E-4E7E-8735-B30000865D1C $\} \&$ Mode $=1$

50. Berger P, Luckmann T. A construção social da realidade. Petrópolis: Vozes; 1995.

51. Brasil. Departamento de DST e Aids. Campanhas de prevenção de Aids; s/d. [site na Internet]. [acessado 2009 set 1]. Disponível em: http://www.aids.gov.br/ pagina $/$ videos $/$ campanhas?page $=2$

52. Ayres JR, Calazans GJ, França Júnior I. Vulnerabilidade do adolescente ao HIV/Aids. In: Vieira EM, Fernandes MEL, Bailey P, McKay A, organizadoras. Seminário Gravidez na Adolescência. São Paulo: Associação Saúde da Família; 1999. p. 97-109.

Artigo apresentado em 21/06/2012

Aprovado em 10/08/2012

Versão final apresentada em 20/08/2012 